\title{
Structures in Specialised Out-patient Palliative Care in Germany - Results of an Online Survey
}

\author{
Papke $\mathbf{J}^{1, *}$, Lux E $A^{2}$ \\ ${ }^{1}$ Faculty of Heath and Nursing Sciences, West Saxon University of Applied Sciences of Zwickau, Germany \\ ${ }^{2}$ Department of Pain and Palliative Medicine Faculty of Health, Witten-Herdecke University, Germany
}

Copyright $\bigcirc 2016$ by authors, all rights reserved. Authors agree that this article remains permanently open access under the terms of the Creative Commons Attribution License 4.0 international License.

\begin{abstract}
Specialised outpatient palliative caring (SAPV) has been available in Germany for nearly ten years. SAPV structures exist in all German federal states but coverage is still not comprehensive. For further development, assessment at the level of care providers, quantitative and qualitative composition of the PCT, networking, coordination and organisational structures is important. This survey was conducted in physicians from independent practices and hospitals if it was known that they worked within SAPV structures with the aim of collecting and analysing data from everyday German healthcare practice. It is the first survey to include physicians from different specializations and to ask specifically about SAPV in Germany. SAPV is undertaken predominantly on a multi-professional basis; qualified general practitioners are the most strongly represented group of specialists. They cooperate closely with colleagues from other specializations and from non-medical professions. Mostly, physicians deliver SAPV alongside their activity in an independent practice or hospital, which further increases the high workload involved. In Germany, SAPV has developed into an essential structural element of palliative care. Its further development must be systematically promoted.
\end{abstract}

Keywords Outpatient Palliative Care, Palliative Network, Nurse, Physician

\section{Introduction}

The option of qualified outpatient caring for people with incurable and progressive diseases and high symptom burden (spezialisierte ambulante Palliativversorgung; SAPV) has been available in Germany since 2007. Care is provided by a multi-professional palliative care team (PCT), consisting of qualified physicians, nurses and other professionals. These teams function as independent organisational units in every county. SAPV structures exist in all federal states but were developed independently and coverage is not yet comprehensive $[1,2]$.

To develop SAPV further, investigation of the structures is required. SAPV is personnel-intensive, so information about the quantitative and qualitative composition of the PCT, networking, coordination and organisational structures is important. The following survey was conducted in physicians from independent practices and hospitals if it was known that they are specialised and work within SAPV structures. Aim of the study was to collect and analyze data from everyday German healthcare practice.

\section{Methods}

A 90-questions-questionnaire was used to collect data about SAPV and its framework. All physicians in Germany who were known to work in SAPV were contacted by postal letters and got the online access for the survey. Data collection and processing was done by the independent research agency Anfomed, Moehrendorf, Germany.

\section{Results}

\subsection{Physician-related Data}

Out of the total of 191 physicians contacted, $64.9 \%$ took part. $88.5 \%$ of the physicians had a specialization: $41.8 \%$ were general practitioners, $23.8 \%$ anaesthesiologists, $17.2 \%$ specialized in internal medicine and $13.9 \%$ were haematologists and oncologists. $11.5 \%$ had two or three specializations. As an additional designation, $96.7 \%$ had "palliative medicine", $21.5 \%$ "pain therapy", 13.2\% "emergency medicine" and 10.7\% "psychotherapy".97.8\% stated that they were part of a SAPV structure.

\subsection{Structure and Organisation of the SAPV Networks}

Each network included an average of $11.6( \pm 14.7)$ physicians, $83.2 \%$ of whom were in independent practice. $88.6 \%$ of the networks included general practitioners, $62.3 \%$ 
anaesthesiologists; $57.9 \%$ haematologists and oncologists and $43.9 \%$ specialists in internal medicine. $75.9 \%$ of the networks involved chaplains, $61.1 \%$ pharmacists, $40.7 \%$ social workers, $30.6 \%$ psychologists, $10.2 \%$ nurses and $7 \%$ psycho-oncologists.

87.4 of the networks had a coordinator, while $63.6 \%$ had a manager. The SAPV structures were generally attached to a practice, hospital or charitable institution. Care was provided in $65.4 \%$ by a PCT; in $6.7 \%$ two and in $13.5 \%$ three teams were involved.

In the case of $69.7 \%$ of physicians, communication was carried out directly with the prescriber of SAPV and in 29.4\% of cases via case management. Supervision was provided in $71.7 \%$ of cases - in half of these it was provided by psychologists. In $91.9 \%$ of networks, regular staff meetings were held: once a week in $30.4 \%$, once a month in $19.6 \%$ or once a quarter in $11.7 \%$. Structured continuing education was given in $87.4 \%$ of networks, which was attended by physicians and nurses together in $93.7 \%$ of cases.

\subsection{Activity in a PCT}

6.6 physicians belonged to a PCT; $84.5 \%$ of the PCT was also made up of general practitioners, $57.1 \%$ of anaesthesiologists and haematologists/oncologists and 40.5\% of specialists in internal medicine. $9.82( \pm 8.18)$ nursing staff belonged to a PCT. Cooperation in the network was rated by $60 \%$ of physicians as "very good", by $36 \%$ as "good" and by $4 \%$ as "neutral".

Patients were always referred via hospitals; $94.1 \%$ by family doctors and $76.4 \%$ by other physicians in independent practice and by those in the SAPV network.

The spectrum of diseases involved oncological, cardiovascular, neurological and pulmonary diseases. A patient was treated for an average of 26.6 ( \pm 16.6$)$ days; a contact lasted an average of $50.9( \pm 23.0)$ minutes. 81.4 $( \pm 14.5) \%$ of patients were able to die at home.

\subsection{Physician Activity in and in Addition to the SAPV}

$78.3 \%$ of palliative care physicians worked in independent practice and $15.5 \%$ in a hospital. In the case of the physicians who were not predominantly engaged in palliative care, $56.3 \%$ (in independent practice) and 52.9\% (hospital physicians) spent less than half their working hours on their SAPV activity. The time spent on organisation and documentation was 25 to $50 \%$ of treatment time by $33.7 \%$ of those in independent practice and less than $25 \%$ by $53.5 \%$. Among the physicians employed in hospital, $35.3 \%$ needed between 25 and $50 \%$ of their time and $41.2 \%$ needed less than $25 \%$ for administration.

Each physician cares for an average of 59 patients per year; looking after 9.7 (maximum 51) patients at the same time. $26.8 \%$ of those surveyed were able to use an official car, which included $21 \%$ of physicians in independent practice and $35 \%$ of hospital physicians.

\subsection{Documentation and Quality Management}

$28.8 \%$ of physicians used a quality management (QM) system; $87.4 \%$ used a tool to document therapy and care. Documentation was $48.6 \%$ hand-written and $38.3 \%$ electronic. The time spent on documentation accounted for $25.96 \%$ of the total time spent.

\subsection{Personal Ratings}

$66 \%$ of physicians reported that they were able to care for patients satisfactorily; there was a high need for SAPV but there was too little awareness of it and it was underused. On the other hand, it was stated that too little time was left available for SAPV in everyday practice and too few physicians were available to undertake it. There was a need for improvement with regard to remuneration, the structure of bureaucracy and documentation, simplifying dealing with opioids and emergency prescriptions of opioid analgesics. $75.7 \%$ reported problems with the health insurance schemes meeting costs.

\section{Discussions}

In Germany since 2007 SAPV makes it possible for seriously ill and dying people to be cared for at home but is personnel-intensive, time-consuming and there is often insufficient awareness of its availability. The physicians involved predominantly work in independent practice or hospitals. General practitioners were represented in almost $90 \%$ of all SAPV networks, which makes SAPV the domain of the qualified specialist general practitioner.

\subsection{Multi-Professionalism and Team Interactions}

SAPV networks are multidisciplinary. Multi-professionalism and cooperation are essential preconditions for the care of patients and their relatives; but are not, on their own, a guarantee of quality of care. Good communication between team members is the basis of inter-professional cooperation, utilisation of synergies and overcoming conflicts [3]. Cooperation within the PCT was rated as good and very good by $96 \%$. An important result is that $81.4 \%$ of patients cared for were able to die at home. This means that SAPV meets its most important targets.

\subsection{Shortcomings and Challenges}

The patients cared for are predominantly oncology patients but the proportion of non-oncology patients' increases steadily [4]. Many patients with non-oncological underlying diseases show symptom clusters similar to cancer patients [5]. Therefore non-oncology patients should also receive competent palliative care and this service should be rewarded.

Even though $60 \%$ of participants rate cooperation as positive, regular staff meetings are held in one third of PCT only. There are often shortcomings in the cooperation 
between medical and psychosocial professional groups [6].

Supervision was provided in three quarters of the SAPV networks. This is expressly recommended as a contribution to quality development and assurance [7]. Multi-professionalism, accessibility and expertise on the part of the physicians and nurses are essential requirements. They present challenges particularly for the physicians who are employed predominantly in independent and clinical practice as shown by the 50 -minute contact time and fact that about 10 patients are cared for at the same time. The problem is aggravated further by irregular working hours and a high amount of documentation. In addition, high quality standards are also required to ensure competent care [7]. The low proportion of SAPV networks that have QM systems is a rather sobering result.

\subsection{Approaches to Improving SAPV}

The development of SAPV in Germany has been regionally-based and heterogeneous. For example, there is no consistent documentation and remuneration, which in turn causes differences in the way SAPV is structured [6].

Although a legal right to SAPV has existed for more than eight years now, only two thirds of general practitioners are aware of it [8]. In future, awareness, particularly among general practitioners, of the aims, contents and prescription of SAPV must be improved and the development of care promoted.

\section{Conclusions}

This is the first survey to include physicians from different specializations and to ask specifically about SAPV structures in Germany.

In Germany, SAPV is provided predominantly on a multi-professional basis; qualified general practitioners are the most strongly represented group of specialists. They cooperate closely with colleagues from other specializations and from non-medical professions. As a rule, physicians deliver SAPV alongside their activity in an independent practice or hospital, which further increases the high workload involved. In Germany, SAPV has developed into an essential structural element of palliative care. Its further development must be systematically promoted.

\section{Acknowledgements}

The authors want to thank the TEVA Pharmaceutical Industries Company for supporting the project, especially for assistance in translation into English language.

\section{REFERENCES}

[1] Deutscher Hospiz- und Palliativverband e.V. http://www.dhpv.de/service_zahlen-fakten.html

[2] Gemeinsamer Bundesausschuss. Bericht an das Bundesministerium für Gesundheit über die Umsetzung der SAPV-Richtlinie für das Jahr 2012.https://www.g-ba.de/dow nloads/17-98-3557/Bericht-Evaluation-SAPV-2012.pdf

[3] Klarare A, Hagelin CL, Fürst CJ, Fossum B.: Team interactions in specialized palliative care teams: a qualitative study. J Palliat Med 2013; 16: 1062-1069

[4] Hess S, Stiel S, Hofmann S et al.: Trends in specialized palliative care for non-cancer patients in Germany - Data from the National Hospice and Palliative Care Evaluation (HOPE). Europ J Intern Med. 2014; 25: 187-192

[5] 5] Stiel S, Matthies DM. Seuß D et al.: Symptoms and Problem Clusters in Cancer and Non-cancer Patients in Specialized Palliative Care-Is There a Difference? Pain Symptom Manage 2014; Jan 10. pii: S0885-3924(13)00638-6 [Epub ahead of print]

[6] Jansky M, Lindena G, Nauck F.: Stand der spezialisierten ambulanten Palliativversorgung (SAPV) in Deutschland Verträge und Erfahrungen (Specialized Out-Patient Palliative Care (SAPV) in Germany -Contracts and Experiences) Z Palliativmed 2011; 12: 164-174

[7] Empfehlungen des GKV-Spitzenverbandes nach § 132d Abs. 2 SGB V für die spezialisierte ambulante Palliativversorgung vom 23.06.2008 in der Fassung vom 05.11.2012http://www.gkv-spitzenverband.de/media/dokume nte/krankenversicherung_1/hospiz_palliativversorgung/Pallia tiv_Empfehlungen nach 132d_Abs_2_SGB_V_05-11-2010 2.pdf)

[8] Schneider N, Engeser P, Behrmann M et al.: Spezialisierte ambulante Palliativversorgung. Die Erwartungen von Hausärzten. Schmerz 2011; 25: 